\title{
Génesis y problematización de la ley de acoso laboral en Colombia*
}

\author{
Enrique SECO MARTÍN \\ Consultor Independiente \\ secomartin@yahoo.es \\ Carmen Marina LÓPEZ PINO \\ Miembro Titular de FLACSO-España y Especialista para América Latina \\ del ProGRANT Proposal Writing for Research Grants \\ Universidad de Colonia, Alemania \\ carmen982000@yahoo.com
}

Recibido: 18-07-2013

Aceptado: 10-02-2014

\begin{abstract}
RESUMEN
El mobbing es un fenómeno que vivencian en silencio cotidianamente muchos trabajadores y trabajadoras en el mundo. Colombia es uno de los pocos países que ha reglamentado jurídicamente de forma específica este fenómeno. El artículo aborda la génesis y problematización de la Ley 1010 de 2006 sobre acoso laboral, desde la perspectiva del campo jurídico propuesto por Bourdieu (2000). La hipótesis de partida es que su débil problematización respondió al desequilibrio de poder en el campo de las relaciones laborales y a las estrategias elaboradas por los diversos actores (Estado, empresarios y trabajadores) para dar contenido o no a dicha Ley, lo que se tradujo en una débil eficacia de la misma. El abordaje metodológico se realizó a través de un minucioso estudio documental y cualitativo.
\end{abstract}

Palabras clave: legislación laboral, acoso laboral, sociología jurídica, Ley 1010/2006, relaciones laborales.

\section{Problematization and genesis the mobbing law in Colombia}

\begin{abstract}
Mobbing is a phenomenon they experience in daily silence many workers in the world. Colombia is one of the few countries that has specifically legally regulated phenomenon. The article discusses the genesis and questioning of Law 1010 of 2006 on workplace bullying from the perspective of the legal field proposed by Bourdieu (2000). The hypothesis is that its weak problematization responded to the imbalance of power in

* Este artículo recoge parte de los resultados de la investigación Habitus y prácticas de acoso laboral y su forma de resolución jurídica en Colombia, financiado por el Fondo de Investigación de la Universidad del Rosario (FIUR) y adelantado conjuntamente por los grupos de investigación "Ética aplicada, trabajo y responsabilidad social” de la Escuela de Ciencias Humanas y por el grupo de "Derechos Humanos de la Facultad de Jurisprudencia”. El análisis de la información es trabajo y responsabilidad de los autores.
\end{abstract}


the field of labor relations and the strategies developed by different actors (government, employers and workers) to provide content or not the Act, which resulted in a weak effectiveness thereof. The methodological approach was made through a careful documentary and qualitative studio.

Keywords: labor legislation, mobbing; legal sociology, 1010/2006 Act, labor relations.

\section{REFERENCIA NORMALIZADA}

Seco Martín, E. y López-Pino, C.M. (2015). “Génesis y problematización de la ley de acoso laboral en Colombia”. Cuadernos de Relaciones Laborales, Vol. 33, núm. 1, p. 119-147.

SUMARIO: Introducción. 1. Marco analítico. 2. Resultados. 2.1. El campo de las relaciones laborales en Colombia. 2.2. Contexto y motivos de la regulación jurídica del acoso laboral. 2.3. Estrategia: conformación de una coalición de apoyo. 2.4. El poder de la coalición de apoyo del gobierno Uribista. 2.4.1. Modificaciones al Proyecto de Ley 88 de 2004. 2.4.2. Ley 1010 de 2006: una ley sin fuerza jurídica. 3. Conclusiones. 4. Anexo. 5. Bibliografía.

\section{Introducción}

El estudio de la génesis y problematización de las leyes ha sido un campo poco explorado por la sociología jurídica a nivel internacional y en Colombia. Por ello, el interés de este artículo es dar cuenta de este proceso que dio lugar a la Ley 1010 de 2006 de acoso laboral.

El acoso laboral es un fenómeno que desde la década del ochenta empieza a configurarse como un problema social en los países desarrollados. Este es visibilizado por la academia (Leymann 1996 y Zapf \& Gross 2001) y a principios del presente siglo alcanza mayor atención en el campo jurídico europeo y latinoamericano (regulación en Suecia, Francia, Bélgica, España, Italia, Australia, México y la provincia de Buenos Aires en Argentina). Colombia es uno de los primeros países en legislar este fenómeno a través de una ley específica (Ley 1010 de 2006), contribuyendo a su visibilización.

Según Leymann, el "mobbing” hace referencia a un proceso de interacción social en el trabajo por el cual un individuo es atacado por uno o más individuos, de manera persistente, llevando al hostigado a una posición de indefensión con un alto potencial de exclusión (1996: 6). Es así como el acoso laboral se relaciona con el ejercicio del poder, con la vulneración de la autonomía y con la estigmatización de los individuos, bien sea por parte de miembros de la jerarquía organizacional o por parte de sus compañeros de trabajo o de un subalterno.

Resultados del acoso laboral son el miedo, la humillación, el descrédito, la degradación de las víctimas, la pérdida de autoestima, con todas las implicaciones psicosociales que se podrían esperar de una experiencia traumática prolongada. Cada uno de estos trastornos tiene su propio elenco de síntomas particulares, que varían en severidad y tienen la capacidad de desestabilizar a las personas psicológica y funcionalmente. Tales traumas representan una lesión grave que tiene secuelas en la identidad y las relaciones interpersonales y sociales de los afectados.

En Colombia el mobbing empieza a configurarse como un problema social a través de la Ley 1010 de 2006, propuesta que surge del campo político en el marco 
de un gran desprestigio social del país a nivel internacional por la violación de los derechos humanos y laborales.

Partiendo de la teoría del campo jurídico de Bourdieu (2000 y 2001b) y del concepto de problematización de Foucault (1999), el artículo reconstruye el proceso de génesis de la Ley 1010 de 2006 a partir del momento en que ésta es presentada ante el Congreso para su discusión y aprobación. Los resultados de la investigación indican que la débil problematización de la Ley de acoso laboral en Colombia respondió a factores externos y a las estrategias de los actores del campo de las relaciones laborales, las cuales son el resultado del desequilibrio de poder y de los habitus de negociación de sus actores.

La propuesta de ley sobre acoso laboral parte del Ministerio de Protección Social y es presentada por miembros de la coalición del presidente Uribe. El Proyecto arranca el 29 de Julio de 2004 con la radicación en la Cámara y en Enero de 2006 se publica la Ley 1010 en el Diario Oficial.

El estudio se apoya en un diseño documental y cualitativo, que permite captar la realidad como un proceso construido socialmente por los actores en interacción y negociación. La parte documental está compuesta por la recolección y análisis de 25 documentos que recogen las actas de las discusiones celebradas en la Cámara, el Senado y las respectivas comisiones de ambas instancias que debatieron los Proyectos de Ley 088 de 2004 de la Cámara y 236 de 2005 del Senado, que finalmente fueron aprobados convirtiéndose en la Ley 1010 de 2006 de Acoso Laboral. Mientras la cualitativa se apoya en entrevistas semiestructuradas realizadas a diversos actores ${ }^{1}$.

La ausencia de investigaciones sobre la génesis de la ley de acoso laboral motivó indagar esta problemática, además su estudio permite comprender cómo se construye la categoría de acoso laboral en el campo jurídico en Colombia y, en alguna medida, reflexionar sobre la dificultad de configurar este fenómeno como un problema social.

Para dar respuesta a la pregunta de investigación, primero, se expone el marco analítico de partida; segundo, se caracteriza el campo de las relaciones laborales en Colombia; tercero, los motivos que indujeron al gobierno a colocar en la agenda del campo jurídico esta problemática; cuarto, las estrategias de los actores (Estado, empresarios y sindicatos) para dar o no contenido a esta Ley y, por último, las conclusiones.

${ }^{1}$ Para el análisis particular de este artículo se utilizaron 15 entrevistas de las 48 realizadas en el estudio. Se entrevistó a jueces, líderes sindicales y personas cercanas al proceso de redacción de la Ley. Igualmente, se analizaron borradores y actas de discusión de la Ley 1010 en comisiones y plenos de la Cámara y el Senado. La sistematización de la información documental y cualitativa se realizó a través del software ATLAS.ti.6. 


\section{Marco analítico}

¿Qué es problematizar? Partiendo de Foucault, Ibáñez plantea:

(...) es algo muy fácil de definir y extraordinariamente difícil de llevar a la práctica. Se trata de conseguir que todo aquello que damos por evidente, todo aquello que damos por seguro, todo aquello que se presenta como incuestionable, que no suscita dudas, que, por lo tanto, se nos presenta como aproblemático, se torne precisamente problemático, y necesite ser cuestionado, repensado, interrogado, etc. (...) Es lograr entender el cómo y el por qué algo ha adquirido su estatus de evidencia incuestionable (1996: 54).

En este sentido, para Foucault problematizar un fenómeno no significa representar un objeto preexistente, así como tampoco crear un objeto que no existe. Es el conjunto de las prácticas discursivas o no discursivas que hacen que algo entre en el juego de lo verdadero y de lo falso y lo constituye como objeto para el pensamiento (bien sea en la forma de la reflexión moral, del conocimiento científico, del análisis político, etc.) (1999: 371). Estas prácticas son concebidas en un sentido histórico y pueden desencadenar en la construcción de un fenómeno como un problema social en el sentido dado por Lenoir et al (1993), es decir, en la medida en que se realice un trabajo de reconocimiento social, legitimación e institucionalización.

El proceso génesis de la Ley de acoso laboral ilustra cómo la lucha que se da en el campo jurídico no es la lucha por la eficacia o por la justicia, sino la lucha entre los diversos agentes por el monopolio de decir qué es el derecho, por establecer cuál es la distribución del buen orden. Según Bourdieu, es la lucha en la que se enfrenta agentes investidos de una competencia inseparablemente social y técnica, capacidad socialmente reconocida de interpretar un cuerpo de textos que consagra la visión legítima, recta, del mundo social (2001b:160).

Sin duda, el derecho es la forma por excelencia del poder simbólico, configura esquemas de percepción, apreciación y acción que están en el origen de nuestra construcción del mundo social producido por un trabajo histórico colectivo (Bourdieu 2001b: 203). En este sentido, el derecho ejerce una eficacia específica, se define por la oposición a la aplicación fundada sobre la pura coacción.

Según Bourdieu, las prácticas y los discursos jurídicos están doblemente determinados, en primer lugar, por las relaciones de fuerza específicas que le confieren su estructura y que orientan las luchas, y que trascienden el campo jurídico. En segundo lugar, por la lógica interna de las acciones jurídicas que limitan en cada momento el espacio de lo posible y, con ello, el universo de soluciones propiamente jurídicas (2001b: 159).

Las relaciones de fuerza dependen de los recursos de poder de los actores (es decir, de sus capitales), los cuales son la base para la elaboración de las estrategias, que están a su vez determinadas por los habitus y prácticas de negociación. Según Bourdieu (2001b), el habitus puede definirse como el conjunto de estructuras 
mentales, de categorías de percepción, apreciación y acción que constituyen el principio unificador de las diferentes prácticas.

En este sentido, la hipótesis de partida es que la débil problematización de la ley de acoso laboral o mobbing en Colombia respondió al desequilibrio de poder en el campo de las relaciones laborales y a las estrategias elaboradas por los diversos actores (Estado, empresarios y trabajadores) para dar contenido o no a dicha Ley.

De ahí que interesa desentrañar, por un lado, la génesis, es decir, qué motiva la puesta en escena en el campo jurídico el fenómeno del mobbing y; por otro, las luchas de poder y las estrategias que se tejen para determinar las prácticas jurídicas: la forma en que se concibe y define el acoso laboral, la manera de arbitraje y juzgamiento de los daños y de las responsabilidades, y las formas en que se concibe la reparación y el castigo. Desentrañar el proceso de problematización de la Ley 1010, permite comprender, en parte, la eficacia de la misma y la construcción del acoso o mobbing como un problema social.

\section{Resultados}

En este apartado primero se caracterizan las relaciones laborales en Colombia; segundo, se expone el contexto y los motivos de la regulación del mobbing en el país; tercero, se analizan las diferentes estrategias de los actores del campo de las relaciones laborales (Estado, empresa y sindicatos); y por último, se reflexiona sobre la eficacia de la Ley 1010.

\subsection{El campo de las relaciones laborales en Colombia}

Dombois y Pries caracterizan las relaciones industriales en Colombia como "poco institucionalizadas, heterogéneas y desdibujadas", incluso, en la fase de mayor expansión económica y fortaleza relativa de las organizaciones sindicales (años 60 y 70); situación ésta que se acentúa en la fase de la crisis de los ochenta y con el proceso de apertura económica y reestructuración del Estado, adelantados por los diversos gobiernos a partir de la década del noventa. La precaria institucionalización está determinada por el marcado desequilibrio de fuerzas entre capital y trabajo, y por la configuración de un sistema de relaciones laborales producto de la política estatal de desarrollo y de modernización y no de fuertes confrontaciones sociales y políticas (Dombois y Pries, 2000: 125 y Palacios, 1995:238).

Relaciones industriales basadas en: 1) regulación “minimalista” (salario mínimo, prestaciones sociales, límites al despido improcedente), que cubre a menos del $45 \%$ de la población ocupada ${ }^{2}$, debido a la alta informalidad existente; 2) amplia

\footnotetext{
${ }^{2}$ Las tasas de informalidad en el país ha alcanzado el 57\% de la población ocupada y para enero de 2013 era de $51 \%$ (Dane, www.dane.gob.co).
} 
autonomía de gran parte de los empresarios para regular la organización del trabajo y las relaciones laborales; 3) relativa autonomía del Estado para adelantar procesos de regulación jurídica ${ }^{3}$. Buena parte de esta regulación se ha llevado a cabo sin la participación de las organizaciones sindicales, bien a través de la figura del Estado de excepción (caso del Código Sustantivo de Trabajo, por ejemplo) o por medio de coaliciones de apoyo formadas por el gobierno (Ley 50/1990 de flexibilización laboral y Ley 789/2002 de reducción de costos laborales), desconociendo en gran medida los intereses de los trabajadores; y 4) débil legitimación del quehacer sindical.

Un campo laboral atomizado por el predominio de sindicatos de base o de empresa, y por la casi inexistencia de sindicatos de rama; lo que genera una diversidad de formas de relaciones laborales, que poco propician la democratización de las condiciones de empleo y de trabajo (López, 2002).

A diferencia de prácticas corporativas como las existentes en algunos países europeos y latinoamericanos, en Colombia no ha habido un reconocimiento de las organizaciones sindicales como actores válidos de negociación. El informe final PNUD (2010) señala:

Más allá de las restricciones normativas, desde el mismo momento en que se reconoce en 1919 el derecho de huelga y en 1931 el derecho a constituir sindicatos, ha existido en amplios sectores de la dirigencia y del Estado una gran desconfianza hacia la inevitable y necesaria relación entre sindicalismo y política. En especial, cuando la actividad sindical se ha desplegado en contra de políticas económicas o laborales que afectan a los trabajadores, se ha acusado a las organizaciones sindicales de participación indebida en política (2010:20).

Según la Corporación Nuevo Arco Iris, a partir de la década del ochenta, "las élites locales, representadas en dirigentes políticos y empresarios, en asocio con miembros de la Fuerza Pública y paramilitares, realizaron una acción generalizada y sistemática de exterminio de dirigentes sindicales para cobrarles su participación en la lucha laboral y política al lado de expresiones legales de las guerrillas en un tiempo de negociaciones de paz y búsqueda de una apertura democrática” (2010: 64-65).

3 Refiriéndose a la Reforma del 68, Navajas trae a colación el peso relevante del ejecutivo en la regularización de las relaciones laborales. “... durante los gobiernos del llamado "Frente Nacional" han caído bajo la andanada oficial numerosas conquistas de los trabajadores. Se recortó el derecho de huelga, se institucionalizaron los contrapliegos patronales, se montaron los Tribunales de Arbitramento Obligatorio, se oficializó el sistema de los contratistas, se facultó al presidente del república para ilegalizar cualquier huelga,... y a los trabajadores oficiales se les ha venido arrebatando los derechos de asociación y contratación colectiva al ser clasificados como empleados públicos, gracias a la aplicación de la Reforma Administrativa adelantada por el gobierno a partir de 1968... (1974: 223). 
En este período, el narcotráfico se infiltra en gran parte del tejido económico, social y político del país recrudeciendo la violencia a través de la guerra sucia, poder fáctico del cual no escapan los líderes sindicales. El informe de Dejusticia destaca que, según Amnistía Internacional, desde 1991 hasta 2007 se registran 2.245 muertes, 3.400 amenazas y 138 desapariciones forzadas a dirigentes sindicales; y la Embajada de EEUU apoya lo anterior, "al indicar que para 2007, y pese a los compromisos adquiridos con la OIT para la creación de la subunidad especializada, sólo se han producido 105 sentencias referidas a 86 víctimas, es decir un nivel de impunidad del 96,8\%” (La Rota, et. al. 2010: 24).

La histórica debilidad de las organizaciones sindicales se ha acentuado en las últimas décadas por la estigmatización de los sindicatos ${ }^{4}$ y sindicalistas, por la guerra sucia, y por el proceso de reestructuración empresarial y estatal, asociado este último a la flexibilidad laboral, a despidos colectivos y al crecimiento de los pactos colectivos ${ }^{5}$, lo cual reduce la tasa de sindicalización al $4 \%$ de la población ocupada.

En este marco de relaciones labores se inscriben la génesis y problematización de la Ley 1010 sobre acoso laboral en Colombia.

\subsection{Contexto y motivos de la regulación jurídica del acoso laboral - La homogenización de la ley}

Desde la década del noventa, los diversos gobiernos colombianos adelantan una estrategia cada vez más agresiva de apertura de los mercados que se traduce en la gestión de tratados de libre comercio, en especial con países desarrollados. Esta estrategia es acorde con la tendencia de homogenización de las normas a nivel internacional, como condición para participar en el juego de la globalización (Bourdieu, 2001a). Dicho principio engloba hoy la construcción de estándares internacionales en materia laboral para garantizar reglas del juego comunes entre los Estados. Esto se traduce en procesos de regulación y desregulación normativa con efectos en el campo jurídico ${ }^{6}$.

Cabe preguntarse: ¿Por qué el mundo más desarrollado mira con desconfianza la desregulación laboral existente en países como Colombia y China? Como señala

${ }^{4}$ El estudio del FIP, resultado de un análisis de prensa, señala: “De una forma o de la otra, el sindicalismo se convierte en un 'otro' que nunca va a poder acomodarse a un funcionamiento social de 'normalidad', ya que su esencia está estrechamente ligada a la confrontación y a la ruptura de la normalidad” (2010:26).

${ }^{5}$ El Pacto Colectivo es una figura legal utilizada por los empresarios que supone la exclusión de los sindicatos como actores válidos para la negociación colectiva.

${ }^{6}$ Es así como resultado de presiones internas y externas, el gobierno colombiano adelanta una legislación laboral en torno a reducir costos laborales y a flexibilizar el mercado laboral (Ley 50/90; Ley 789/2002). 
Bourdieu el proceso de globalización no es unidimensional: se predica la liberación de los mercados pero, al tiempo, se despliega un disimulado proteccionismo (2001a: 258-260). Los países desarrollados presionan a los países en desarrollo a intentar unificar las normativas laborales con miras a colocar límites a lo que se llama dumping social, es decir, competencia desleal basada en bajos salarios y debilidad de la norma laboral. En este sentido, es una liberalización que se apoya en la formalización de las reglas del juego (restricciones en términos de Bourdieu).

La idea anterior es acorde con la presión de EE.UU para la firma del Tratado de Libre Comercio (TLC) con Colombia, el cual demandó reformas para regular el mercado laboral colombiano con vistas a reducir la brecha existente con respecto al mercado laboral estadounidense. Precisamente la homogeneización de la norma se inscribe en el proceso de liberalización del comercio internacional.

En este contexto se encontraría el papel de la OIT como garante de esa homogeneización de la norma laboral (derecho social) de cara a la apertura del comercio mundial. Y, en el mismo plano, la preocupación del gobierno y de los legisladores colombianos por la imagen internacional del país en materia laboral.

\section{- La estrategia del gobierno: acumular capital simbólico}

Desde la década del ochenta, las organizaciones sindicales no logran escapar de la violencia política existente en el país. "Pero solamente a raíz de las negociaciones finales para la firma de un tratado de libre comercio de Colombia con los Estados Unidos, por un lado, y con la Unión Europea, por el otro, se ha hecho conciencia en un contexto más amplio de opinión pública internacional sobre la dimensión de la violencia física, irregular y extralegal ejercida contra los sindicalistas" (Dombois, 2012: 113).

Entre 1986 y 2006 murieron asesinados 2.669 sindicalistas. Según la Escuela Nacional Sindical, las cifras son contundentes, "en Colombia se presentó el 63,12\% de asesinatos de la década [1999-2009]. Situaciones similares, aunque en menor medida, se presentaron en Filipinas con una participación de 5,44\%, y Guatemala, con una participación de 3,45\% del total de asesinatos del mundo” (ENS 2010: 2). 
Tabla 1. Homicidios sindicalistas colombianos, enero de 1986-2006

\begin{tabular}{|l|c|l|c|c|c|c|}
\hline Año & $\begin{array}{c}\mathrm{N}^{\mathrm{0}} \\
\text { Homicidios }\end{array}$ & Año & $\begin{array}{c}\mathrm{N}^{\mathrm{o}} \\
\text { homicidios }\end{array}$ & Año & $\begin{array}{c}\mathrm{N}^{\mathrm{o}} \\
\text { homicidios }\end{array}$ & $\begin{array}{c}\text { Total } \\
1986- \\
2006\end{array}$ \\
\hline 1986 & 36 & 1993 & 201 & 2000 & 138 & \\
\hline 1987 & 73 & 1994 & 104 & 2001 & 193 & \multirow{2}{*}{2.669} \\
\hline 1988 & 138 & 1995 & 229 & 2002 & 191 & \\
\hline 1989 & 96 & 1996 & 277 & 2003 & 101 & \\
\hline 1990 & 58 & 1997 & 171 & 2004 & 95 & \\
\hline 1991 & 96 & 1998 & 98 & 2005 & 72 & \\
\hline 1992 & 141 & 1999 & 83 & 2006 & 78 & \\
\hline
\end{tabular}

Fuente: Banco de Datos de Derechos Humanos ENS. En: ENS, 2010, p. 1.

Sumado a esto, Colombia contaba en esos años con una alta incidencia de observaciones de la Comisión de Expertos en Aplicación de Convenios y Recomendaciones de la OIT (2012). Entre 1990 y 2006, el país recibe 58 observaciones, vinculadas a la necesidad de reconocimiento de la negociación colectiva para los empleados públicos, así como a sancionar las prácticas empresariales encaminadas a privilegiar los pactos colectivos. Son reiterativos los llamados al respeto al derecho de sindicalización y de negociación colectiva.

A raíz de las discusiones que tuvieron lugar en el seno de la Comisión de Normas de la Conferencia Internacional del Trabajo en el 2005, en junio de 2006 se lleva a cabo la actualización del acuerdo tripartito en el marco de la OIT por la libertad sindical y la democracia; cuyos objetivos son promover el trabajo decente y la defensa de los derechos fundamentales de los trabajadores, de sus organizaciones sindicales y de la libre empresa.

En el marco de la estrategia de negociación de tratados de libre comercio con países desarrollados como EE.UU., el gobierno de presidente Uribe sufre presiones internas y externas por el cumplimiento de los acuerdos internacionales promovidos por la $\mathrm{OIT}^{7}$, y esta percepción está presente en el espíritu de la aprobación de la Ley 1010. En el Estudio de Antecedentes del proyecto de Ley 88/2004 (República de Colombia, 2005a: 6) se hace referencia al Convenio 155 de la OIT (1981), sobre la seguridad y la salud de los trabajadores y el medio ambiente de trabajo; y a la

\footnotetext{
${ }^{7}$ http://www.ipitimes.com/tlc021506.htm, noticias como esta fueron reiteradas en dichos años.
} 
Declaración de la OIT (1998), relativa a los principios y derechos fundamentales en el trabajo. El acoso laboral está inserto en la discusión del trabajo decente ${ }^{8}$.

Para analizar la importancia de factores externos relacionados con la estrategia del gobierno del presidente Uribe de construcción de capital simbólico a nivel internacional, es importante visibilizar cómo el gobierno nacional busca disminuir las presiones internacionales y abanderar la lucha contra la violencia en el trabajo ${ }^{9}$. Es recurrente considerar las palabras del Senador Ponente durante el segundo debate en el Senado.

Por lo tanto señora Presidenta yo quisiera que se le diera curso a esta propuesta, ya ha tenido amplia discusión, es su último debate y representa un avance como usted lo recuerda se lo planteamos a los delegados de la Organización Internacional del Trabajo en reciente visita que hicieron al Senado de la República y donde tuvimos la oportunidad de hacer una evaluación de los avances en materia laboral en la Legislación Colombiana, con este proyecto Colombia estaría a la vanguardia en América Latina, no hay un solo país que tenga una legislación laboral en materia de acoso laboral y ello significa dar plenas garantías a los trabajadores para el desempeño adecuado de sus funciones, con esto repito Colombia estaría asumiendo un gran liderazgo y a la vanguardia en materia de legislación laboral y protección de los derechos de tercera generación [Cámara de Representantes 2005: 30].

Como se observa, el Proyecto es presentado ante los delegados de la OIT como un "avance" y "vanguardia” en materia laboral en América Latina. Ello implica un mejoramiento de la imagen de Colombia en instancias internacionales, tal como lo señala el mismo Senador Ponente: "Podríamos recoger inquietudes de los otros Senadores sobre lo que ustedes creen es este Proyecto que repito me entusiasma y que hablaría muy bien del país en materia de avance en las relaciones laborales tanto en el sector privado como público” (Cámara de Representantes, 2005: 30).

Igualmente, el análisis de las actas de discusión en las diferentes comisiones parlamentarias muestra referencias a la aceptación del Proyecto por parte de organizaciones de derechos humanos. En una de estas discusiones, el Senador Ponente destaca el entusiasmo con que dichas organizaciones están percibiéndolo:

${ }^{8}$ El trabajo decente está relacionado con cuatro objetivos estratégicos: 1) Crear Trabajo; 2) garantizar los derechos de los trabajadores; 3) extender la protección social; y 4) promover el diálogo social.

${ }^{9}$ En el marco de las presiones internas e internacionales, en el 2006 se expidió el Decreto 2816, por medio del cual se "diseña y reglamenta el Programa de Protección de Derechos Humanos del Ministerio del Interior y de Justicia”, y en él de manera explícita, se incluyó como población objeto a los dirigentes o activistas de organizaciones sociales, cívicas y comunales, gremiales y sindicales, campesinas y de grupos étnicos (Artículo $2^{\circ}$, numeral $2^{\circ}$ ). 
"Yo he encontrado que hay muchas organizaciones civiles de Derechos Humanos que ven con mucho entusiasmo que nosotros en el Congreso estemos hablando de normas de tercera generación en materia de derecho laboral” (Cámara de Representantes, 2005, p. 29).

La referencia a organizaciones laborales internacionales y a organizaciones de derechos humanos otorga al Proyecto una dimensión que se asocia con la construcción de capital simbólico por parte del gobierno para generar confianza en el país y reconocimiento social a nivel internacional, necesario para avanzar en el proceso de acuerdos de libre comercio. Es así como la Ley de acoso laboral se convierte en un medio y no en un fin en sí mismo.

En el marco de esta estrategia, el gobierno hace uso de sus recursos de poder para posicionar el acoso laboral en el campo jurídico, desconociendo la participación de los actores sociales directamente involucrados: sindicatos, trabajadores/as, operadores judiciales y víctimas, entre otros.

\subsection{Estrategia: conformación de una coalición de apoyo}

En Colombia, tradicionalmente el poder ejecutivo ha tenido un poder significativo en la legislación de las relaciones laborales, bien bajo el principio del Estado de excepción o a través de una estrategia de conformación de una coalición de apoyo (Sabatier, 1987) que le permite a éste adelantar reformas sin la participación de organizaciones sindicales o de movimientos sociales.

La regulación del acoso laboral no se distancia de este habitus, en la medida en que la Ley 1010 no fue el resultado de un proceso de movilización social de los trabajadores y trabajadoras del país, ni siquiera se había construido como problema en el campo social o del trabajo. Aparecía vagamente, a veces asociado al problema del acoso sexual. Ante la urgencia del gobierno por acumular capital simbólico en el contexto internacional, el presidente Uribe se afirma en una estrategia de coalición de apoyo para posicionar esta ley en el campo jurídico.

En el 2004 el gobierno contaba con la mayoría absoluta en ambas Cámaras. El proyecto tuvo como ponentes a senadores y representantes pertenecientes al Partido de la U, que hacía parte de la coalición del presidente Uribe. Hay que destacar que existe consenso por parte de los partidos distantes de la coalición del gobierno (Liberal y Polo Democrático) sobre la necesidad de regular el acoso laboral. Sin embargo, varios de los actores implicados en el escenario laboral (representantes sindicales, representantes de organizaciones empresariales, funcionarios en materia judicial y de trabajo, expertos y víctimas) no participan o lo hacen de manera muy secundaria.

En el Estudio de Antecedentes (República de Colombia 2005a) aparecen referencias a las modificaciones propuestas por dos organizaciones del ámbito laboral: Federación Nacional de Comerciantes (Fenalco) y Sintra Seguridad Social (sindicato de base del Instituto de Seguros Sociales). Esto indica la ausencia de todas las centrales sindicales (CUT, CGT y CTC). El papel del Colegio de Abogados de Antioquia (COLEGA) se encuentra inicialmente ligado a la evaluación del Proyecto desde el punto de vista técnico-jurídico. 
Según una alta funcionaria del Ministerio de la Protección Social el proceso no fue resultado de un espacio de diálogo entre empresarios y trabajadores.

- R: Eso salió, yo me acuerdo que eso fue de... un senador que motivó eso y hubo como... (...) No, pero hubo como una presión... Pero que eso haya surgido por unas...por las centrales obreras, por la ANDI...Eso ni se concertó...

- P: ¿No se concertó?

- R: No ¡nunca! Ni se llevó a un espacio de diálogo [EX Redactora rr.hh. 4].

Aunque los empresarios no están interesados en promover dicha Ley no se oponen abiertamente. En ese momento histórico, el gobierno goza de confianza y apoyo por parte de las organizaciones empresariales (ANDI, FEDEGAN, FENALCO, etc.). Sin embargo, su débil presencia también obedece a sus habitus (formas de interpretar el mundo, de actuar) los cuales orientan sus estrategias. Primero, apuestan a una visión liberal de las relaciones laborales, en la cual el Estado debe intervenir en lo mínimo en la regulación de las relaciones cotidianas de trabajo, de ahí que desestimen una Ley específica para este fenómeno. Segundo, no hay interés en visibilizar y problematizar un fenómeno naturalizado como parte de las relaciones laborales. En este marco de ideas, la Federación Nacional de Comerciantes (Fenalco) es la única organización que los representa y hace parte de la coalición de apoyo del gobierno en la discusión y aprobación de la Ley.

Otro agente social que aparece como desligado de ese diálogo es el representado por las fuerzas sindicales. Un dirigente de una central sindical considera que no fueron consultados en la redacción de la Ley. Señala haberse enterado de la existencia de un Proyecto de Ley cuando éste ya estaba en trámite en el Congreso. Pese a que en las actas de las discusiones en Cámara y Senado no aparece ninguna referencia a propuestas ni de la suya ni de ninguna otra central sindical, el entrevistado señala que trataron de hacer algunos aportes, pero no fueron tenidos en cuenta.

Nosotros como sindicato, nos sentimos desconocidos a la hora de la redacción de la Ley, porque no nos consultaron previamente. A [nuestro sindicato] nunca lo consultaron previamente, para efectos de conocer un proyecto de ley que posteriormente fue la Ley 1010, sino que, simplemente cuando supimos, ya estaba en trámite en el Congreso. (...) Tratamos de hacer algunos aportes, francamente consideramos que no fueron tenidos en cuenta por parte del legislativo y salió la Ley 1010 así como está [S Dirigente 2].

Si bien, la aprobación de la Ley transcurre sin mayor discusión pública expresión de la débil concertación entre Estado, empresarios y sindicatos; la ausencia de las centrales sindicales en este proceso se comprende también en términos de sus habitus los cuales orientan sus estrategias. Primero, ante las crecientes amenazas y asesinatos de trabajadores y dirigentes sindicales, y la permanente violación por parte de las empresas del derecho de sindicalización, la 
estrategia de las centrales sindicales -en especial de la $\mathrm{CUT}^{10}$ - se centra en la lucha política por la defensa del derecho a la vida y a la institucionalización del quehacer sindical, lo que genera una especie de inercia institucional en cuanto a las estrategias a seguir ${ }^{11}$. Segundo, a la naturalización del acoso laboral como consustancial a la relación entre capital y trabajo dentro del sistema capitalista, se suma la poca confianza en la eficacia del campo jurídico para la resolución de este fenómeno y, por último, las llamadas a "negociar" por parte de los gobiernos suelen ser interpretadas y vivenciadas por las organizaciones sindicales como actos formales. Respecto a esto último, un dirigente sindical afirma:

No, no hubo una buena representación nuestra para eso ¿no? Sí nos invitaron para simplemente dar unos conceptos y nosotros los dimos, pero para la redacción del texto, para garantizar que el texto contemplara la visión de la que nosotros creemos que debe tener el acoso, no. (...) Casi todas las normas y leyes que tiene el Congreso nos llaman como para una cosa formal, pero no porque el Congreso recoja el espíritu de nuestras inquietudes. Aquí en Colombia se acostumbra a practicar el verbo participar ¿lo saben? Yo participio, tú participas, él participa, nosotros participamos, vosotros participáis y ellos hacen lo que se les da la gana. Entonces nosotros ya estamos cansados de esas famosas participaciones [S Dirigente 4].

De esta manera se representa la distancia entre los campos político del Parlamento y el sindical ${ }^{12}$. Es en el contexto de una tradición de baja concertación de las relaciones industriales, de prácticas y habitus de negociación, que las organizaciones sindicales no aprovechan este marco de oportunidad para discutir y dar contenido jurídico al acoso laboral. Es así como el texto final de la Ley no otorga función ninguna al actor sindical y la Ley va a ser considerada como se mostrará a continuación como "una ley sin dientes”, debido, entre otras razones, a la ausencia de los actores directamente afectados.

${ }^{10}$ CUT: Central Unitaria de trabajadores, concentra el mayor número de sindicatos y trabajadores del país.

${ }^{11}$ Esta misma inercia institucional se observa en centrales como la CGT y CTC, que centran sus estrategias en la lucha económica.

12 Hay consenso por parte de todos y todas las entrevistadas en la ausencia de concertación. Un representante de una ONG señala: "Fue la idea de unos cuantos que pasó la ley como por decir: sí...Pero no fue una apropiación ni de los trabajadores porque ese es un problema que tienen los trabajadores colombianos y estoy hablando de las tres centrales, que están más metidas en cuestiones de orden ideológico” [EX ONG 2]. 


\subsection{El poder de la coalición de apoyo del gobierno Uribista}

El desarrollo de una ley supone una labor de codificación, de sistematización, racionalización y universalización práctica (Bourdieu 2000). Es decir, un proceso que implica contar con modelos para adelantar decisiones ulteriores, que invocan fundamentos de derecho y que orientan las acciones de los sujetos y de los jueces en la medida en que expresa un sistema cognitivo, práctico y axiológico. En el apartado siguiente se ilustra cómo este proceso, que muchas veces es visto desde la creencia en la neutralidad y autonomía del derecho, responde también a las relaciones de poder y a las circunstancias en que se inscribe.

\subsubsection{Modificaciones al Proyecto de Ley 88 de 2004}

El proceso de aprobación del Proyecto arrancó el 29 de Julio de 2004 y finalizó el 23 de Enero de 2006 con la publicación de la Ley 1010 en el Diario Oficial. Según esos datos, el proceso duró aproximadamente un año y medio. Cabe señalar que los últimos meses fueron los más activos.

El proyecto inicial sufre una serie de modificaciones que quedan incluidas en la Ley 1010. Dichas modificaciones pueden ser clasificadas en dos grandes grupos: aprobadas y no aprobadas. En cuanto a las primeras, éstas se dividieron en positivas y negativas ${ }^{13}$.

- Modificaciones positivas: suponen la ampliación del universo de aplicación de la Ley, de las prácticas tipificadas como acoso laboral (modalidades), el aumento de las sanciones o de las potestades que se otorgan a los funcionarios públicos en la resolución de los casos de acoso.

- Modificaciones negativas: implican cambios restrictivos en el proyecto en cuanto a los aspectos señalados en las modificaciones positivas.

Los ponentes tanto del Congreso como del Senado eran parlamentarios adscritos al Partido de la U, miembro en esa época de la llamada coalición uribista (CU). Buena parte de las modificaciones definidas por este estudio como negativas fueron presentadas por esta coalición de apoyo conformada por el gobierno. También se dieron propuestas por parte de parlamentarios del Partido Liberal y del Polo Democrático Alternativo (coalición de izquierda). Es significativo que un número importante de sus propuestas definidas como positivas no fueron aprobadas. Por

13 También se consideraron las modificaciones neutras, las cuales no suponen cambios sustanciales al Proyecto. Fueron aprobadas siete modificaciones de este tipo. Al igual que en el caso de las modificaciones positivas, seis de las mismas fueron presentadas por iniciativa de senadores (el análisis de los documentos y actas muestra que los aspectos más minuciosos de la discusión de la Ley 1010 se dieron en el Senado), mientras sólo una procedió de la iniciativa de una organización colectiva (Sintra Seguridad Social). 
ejemplo, el senador Angarita, perteneciente a esta última formación, acaparó cinco de las ocho modificaciones no aprobadas (ver tabla $\mathrm{N}^{\circ} 2$, anexo) ${ }^{14}$.

\section{- Modificaciones aprobadas}

\section{- Modificaciones positivas:}

Las modificaciones positivas se orientaron a ampliar las modalidades de acoso laboral; al reconocimiento del daño físico y psíquico como agravante; al establecimiento de sanción -suspensión del cargo provisionalmente- en los casos del sector público; y a la protección de la víctima en la medida en que suspende la evaluación de desempeño. Como se observa en la Tabla $\mathrm{N}^{\circ} 1$ del anexo, tres de las cuatro propuestas fueron presentadas por senadores o representantes de la oposición, y tan sólo una de la CU.

\section{- Modificaciones Negativas}

De todas las modificaciones aprobadas durante el proceso de discusión de la Ley 1010, predominan las que hemos catalogado como negativas (catorce de las treinta modificaciones aprobadas), en las cuales tuvieron un papel importante representantes y senadores de a la bancada uribista (ver tabla $\mathrm{N}^{\circ} 1$, anexo).

Seis de ellas se refieren a limitaciones en la definición del mobbing al introducir atributos que indican que para que haya acoso la conducta debe ser "repetida $y$ pública" y "persistente y demostrable”; a restricciones en el ámbito de aplicación de la Ley en los casos de los contratos de prestación de servicios; a no ampliación de las situaciones que constituyen acoso; y restar al Estado responsabilidad como empleador al introducir la figura de llamamiento en garantía, que permite al Estado fijar responsables de los actos de acoso denunciados.

Cinco de ellas tuvieron que ver con limitaciones establecidas sobre el tratamiento sancionatorio o sobre los actores sancionables, entre ellas el aumento de la relación de atenuantes; o la eliminación del abuso de superioridad como agravante (Senado de la República 2005b: 5).

Tres de ellas restringen también los mecanismos de prevención y de protección de las víctimas: limitación del poder de decisión del "escenario para escuchar las opiniones de los trabajadores" a la hora de adaptar los reglamentos de trabajo a los cambios propuestos por dicha Ley ${ }^{15}$; y la eliminación de la función de los inspectores de trabajo para trasladar de lugar de trabajo a los denunciantes ${ }^{16}$. Por

14 El Presidente del Departamento Administrativo de la Función Pública presentó dos modificaciones, que no fueron aprobadas.

${ }^{15}$ Parágrafo 1 del artículo 9º Senado de la República 2005b: 5.

${ }^{16}$ Parágrafo 3 del artículo 9º Cámara de Representantes 2004b: 7. 
último, llama poderosamente la atención la restricción que supone impedir a terceros poner en conocimiento de las autoridades los casos de acoso laboral ${ }^{17}$.

En estas modificaciones negativas sí encontramos la presencia de una organización empresarial (Fenalco, con tres propuestas aprobadas) y otra organización de juristas (Colega, con dos), las cuales tienen un papel muy activo. El resto de las propuestas correspondió básicamente a la Comisión Uribista.

\section{- Modificaciones no aprobadas}

Un total de ocho propuestas de modificaciones a la Ley no fueron aprobadas. Siete podrían ser consideradas como modificaciones positivas. Varias de ellas se orientaron hacia la consideración del acoso laboral más allá de una conducta pública: la propuesta de especificar que puedan aceptarse medios de prueba en el ámbito privado; la consideración como acoso laboral de las burlas en el ámbito privado; la petición de eliminar los términos "en presencia de compañeros” para la descalificación humillante; y la propuesta de suprimir el carácter "público" de la conducta (artículo $7^{\circ}$ ).

La única modificación no aprobada que se catalogaría como negativa en el sentido de restringir la denuncia de los casos de acoso sería la que solicita el aumento de la cuantía de las multas por queja temeraria (artículo $14^{\circ}$ ).

En general, se podría considerar que, pese al reconocimiento de la magnitud del problema y el entusiasmo expresado en ponencias y debates, el análisis de las actas de Cámara y Senado lleva a afirmar que el paso del Proyecto de Ley por estas instancias tuvo como resultado más limitaciones que desarrollos al contenido del Proyecto, favorecido por la coalición de apoyo conformada por el gobierno del presidente Uribe. Pero ¿cuál es el resultado de estas limitaciones?

\subsubsection{Ley 1010 de 2006: una ley sin fuerza jurídica}

Podríamos resaltar los siguientes aspectos que restan eficacia de la Ley 1010: primero, no se problematiza el concepto de acoso laboral. Segundo, se restringen los actores implicados. Tercero, el sistema probatorio dificulta su corrección y sanción. Y cuarto, las sanciones y reparaciones son casi inexistentes.

Primero, en cuanto a su definición el art. 2o. considera acoso laboral como:

... toda conducta persistente y demostrable, ejercida sobre un empleado, trabajador por parte de un empleador, un jefe o superior jerárquico inmediato o mediato, un compañero de trabajo o un subalterno, encaminada a infundir miedo, intimidación, terror y angustia, a causar perjuicio laboral, generar desmotivación en el trabajo, o inducir la renuncia del mismo (Ley 1010 de 2006).

17 Numeral 2 del artículo 9º Cámara de Representantes 2004b: 9. 
Sin distanciarse de los conceptos básicos construidos en buena parte del campo académico adelantado por psicólogos y psiquiatras (Leymann 1996; Hirigoyen 1999) y recogidos por legislaciones de varios países, la Ley resalta cuatro elementos en la conceptualización del acoso laboral: a) es un acto relacional, b) reiterativo prolongado en el tiempo ("excepcionalmente un sólo acto hostil bastará para acreditar el acoso laboral”, art. $7^{\circ}$ )-, c) intencional, es decir, dirigido contra un individuo, y d) genera daño psicológico e, incluso, físico a la víctima. Estos elementos son centrales en su conceptualización y judicialización, el acoso laboral va a ser interpretado como un acto interpersonal, cuya responsabilidad recae en los individuos, no en las organizaciones. Distante esta definición de las incipientes reflexiones académicas que centran la problemátización en las organizaciones (Liefooghe \& Mackenzie 2001; Martín, M. y Perez, S, 2002; López et al 2011).

Segundo, el alcance de la Ley 1010 se restringe a las relaciones laborales, es decir, no se aplica a las relaciones de prestación de servicios, aspecto éste que sí fue contemplado en el art. $1^{\circ}$ del Proyecto de Ley 88/2004. Esta restricción resulta problemática y permite abrir la discusión al tema de la flexibilización laboral, teniendo en cuenta que buena parte de la población colombiana, especialmente jóvenes, están bajo la forma de contrato por servicios que puede ser, de hecho, un contrato laboral ${ }^{18}$.

Tercero, la Ley 1010 limita su corrección y sanción cuando en su art. $7^{\circ}$ señala: "se presumirá que hay acoso laboral si se acredita la ocurrencia repetida y pública...”. La condición de lo público en determinadas conductas de acoso fue incorporada en la discusión en el Senado, desconociendo que estas conductas son actos que suelen ejercerse y vivenciarse en privado, tal como lo reveló este estudio y demuestran diversos autores (Castillo et al. 2006). A esta condición se suma que la carga de la prueba recae en la víctima, haciendo muy difícil el proceso probatorio, debido a la relación de subordinación y dependencia del trabajador en la relación laboral.

Cuarto, el débil proceso sancionatorio se evidenció desde el primer proyecto presentado ante la Cámara y se suscribió en la Ley 1010. Más aún, aumentaron los atenuantes $\left(\operatorname{art.~} 3^{\circ}\right)$. La compensación máxima es considerar el despido como sin justa causa o el retiro del trabajador acosado como despido indirecto, con su respectiva indemnización económica en los términos del artículo 64 del Código

${ }^{18}$ Un contrato laboral demanda tres elementos: una prestación personal del desempeño del trabajo, una remuneración y relaciones de subordinación. Estas tres situaciones suelen ser vivenciadas por trabajadores con contratos por servicio o mercantiles, de ahí que se hable de la existencia de un "contrato realidad” (Colombia, Corte Constitucional 1997). En esa medida estos trabajadores también podrían acogerse a la Ley 1010, pero debido a la dependencia del trabajador frente al empleador, excepcionalmente el afectado denuncia esta situación. 
Sustantivo del Trabajo. No contempla ningún tipo de reparación económica adicional para la víctima ni la reparación del daño moral ocasionado.

Estos son algunos de los impedimentos que restan eficacia a la Ley 1010, a tal punto que un juez afirme que "es una ley sin dientes" y un inspector de trabajo, de manera misógina, exprese que "la ley de acoso laboral es media mujer enferma". Consideraciones como las anteriores, llevan a los abogados de las víctimas a tramitar algunas conductas de acoso laboral como procesos ordinarios o por las vías civil o penal, sin el amparo de esta la Ley especial ${ }^{1}$, pues los desaniman las limitantes en cuanto al sistema probatorio y de reparación del daño. A este respecto, un juez laboral entrevistado señala:

Póngame cuidado, de acoso laboral, que sólo me permite reclamar la terminación, la indemnización por terminación, cuando yo tengo la vía ordinaria, donde puedo reclamar la terminación, que me reajusten mis horas extras, que me dejaron de pagar unos viáticos, que no me pagaron las vacaciones, ¿ ¿voy a preferir esta vía tan restringida a la del proceso ordinario? No, yo me quedo con la del [artículo] 64 [del CST] y le meto una demanda ordinaria (...) ¿Hay algo nuevo en la norma, si ya estaba consagrada en el 64? ¡Nada! ¡Nada! [F Juez laboral 6].

Si la problematización del acoso laboral hubiese contemplado detenidamente los avances considerados por el Código Sustantivo de Trabajo (CST), el código penal y la Constitución de $1991^{19}$, probablemente esta ley especial hubiese tenido mayor fuerza jurídica.

Algunas de las modalidades que la Ley 1010 establece en la definición del acoso laboral, ya estaban recogidas en el CST. Por ejemplo, el maltrato, la discriminación y la desprotección laboral. El artículo 57, numeral 5 "establece como una de las obligaciones del patrono la de guardar absoluto respeto a la dignidad personal del trabajador" (Cuyana 2011: 14-15).

Cuyana (2011: 100-103) encuentra también antecedentes del acoso laboral en el Código Penal colombiano. Derecho a la igualdad de trato y no discriminación (artículo 147). Adicionalmente, en los artículos 198, 199 y 200 se mencionan actos de acoso. Es de destacar que la vía penal supone reparaciones económica y moral para la víctima, incluso, una sanción penal no contempladas en la Ley 1010. En ese sentido, un dirigente sindical explica que cuando ellos sufren la persecución de las empresas, prefieren demandar por la parte penal: “... si vemos violaciones al derecho de sindicalización, etc. las demandamos en la parte penal. Hemos encontrado más éxito que en la misma Ley esa [de acoso laboral]" [S Dirigente 4].

Si esta ley especial hubiese contemplado la penalización de las conductas de

19 La Constitución de 1991 establece en su artículo 25 que "El trabajo es un derecho y una obligación social y goza de manera especial de protección del Estado, toda persona tiene derecho a un trabajo en condiciones dignas y justas”. 
acoso laboral, tal como lo hizo Francia, España y Suecia, entre otros, posiblemente ésta hubiese tenido mayor fuerza coercitiva en términos legales. Igualmente, si hubiese contemplado un sistema probatorio menos restrictivo y la reparación del daño a las víctimas hubiese sido significativa, la ley ganaría eficacia y legitimidad social.

Lo anterior se evidencia con las pocas querellas depositadas ante el Ministerio de Protección Social y de Salud. Para 2006 se habían presentado 360 querellas, de las cuales en alrededor de 90 se tomaron medidas preventivas, 65 llegaron a conciliación, 90 fueron catalogadas como falta de interés jurídico, 13 fueron a la justicia ordinaria y 16 a la Procuraduría (Motta 2008: 95). El hecho de que el 24\% fueran consideradas como falta de interés jurídico y sólo el 3,6\% alcanzaran la instancia ordinaria, señala la dificultad de adelantar procesos por la vía judicial. En los casos estudiados en la presente investigación, de un total de 68 procesos adelantados en diferentes instancias, sólo cinco fueron resueltos positivamente a favor de la víctima; y cuatro de ellos no acudieron a la Ley 1010, sino a través de la Ley penal y civil.

Para el 2011 el número de querellas se eleva a 1.004, presentándose un crecimiento del 177\% entre 2006 y 2010, sin mayores diferencias por sexo. Si bien, se ha acrecentado el número de querellas, todavía hay un significativo número de provincias que no cuentan con ninguna denuncia o estas no superan las cuatro al año. A esta situación se suma el hecho de que a 2012 muchas empresas aún no habían constituido el Comité de Convivencia Laboral ni contemplado en sus reglamentos mecanismos de prevención del acoso (Ministerio de la Protección Social 2008; Ministerio del Trabajo 2012a; Ministerio del Trabajo, 2012b). Todo ello muestra la débil institucionalización de la Ley 1010 y las débiles medidas para su prevención (Aramburu, L. y Higuera, Z., 2002).

\section{Conclusiones}

Llama la atención cómo una Ley cuya pretensión era la regulación jurídica del acoso laboral, para su prevención, corrección y sanción -considerada como un avance en el campo laboral- termina siendo una Ley sin mayor eficacia jurídica.

¿Cómo comprender este fenómeno? Desde el marco analítico propuesto por Bourdieu, la institucionalización en el campo jurídico de un problema social como el acoso laboral obedece a luchas de poder entre sujetos pertenecientes a diversos campos que se disputan por definir qué es el acoso y cómo judicializarlo, de ahí su arbitrariedad.

La poca eficacia de la Ley como instrumento jurídico está asociada a su débil problematización, lo cual es resultado del desequilibrio de poder en el campo de las relaciones laborales, caracterizado por débiles procesos de concertación entre Estado, empresa y organizaciones sindicales. Esta circunstancia histórica, ha configurado una serie de prácticas y habitus de negociación de los diferentes actores, que contribuyen a explicar sus estrategias para dar o no contenido a la Ley 1010. 
Primero, si bien la génesis de la Ley parte del campo político, espacio por excelencia de reconocimiento en la construcción de un problema social, no se dio una tarea de formulación pública que convocara a los diversos sectores de la sociedad: trabajadores y trabajadoras, víctimas, organizaciones sindicales y empresariales, expertos y operadores judiciales, para convertir el acoso en parte del interés general. Es por ello que no fue una ley consensuada ni tuvo un trabajo previo de toma de conciencia y de formulación social, indispensable para su problematización, institucionalización y legitimación.

Segundo, esta Ley es la expresión de intereses políticos que van más allá del acoso laboral como forma de violencia en el trabajo y como categoría social a construir. Es decir, su regulación no se convirtió en un fin en sí mismo, fue un medio para acumular capital simbólico. Respondió al interés del gobierno en reconstruir la imagen del país a nivel internacional, distante del respeto a los derechos humanos y laborales. Estrategia adelantada en el marco de un proceso de homogenización de la norma laboral, que impulsa la mayor unificación de las reglas del juego entre países que participan del comercio internacional. Consecuencia de ello, el campo jurídico no siempre responde a luchas e intereses internos sino a presiones externas, que llevan a desestimar la problematización del fenómeno como tal.

Tercero, el desequilibrio de poder en el campo de las relaciones laborales favorece la estrategia de coalición de apoyo adelantada por el gobierno y contribuye a explicar cómo éste logra aprobar la Ley al mismo tiempo que la vacía de contenido social y jurídico. Sin embargo, este vaciamiento de contenido no se explica exclusivamente por las ideologías que sustentan los grupos de actores tal como se sostendría desde el marco analítico de "Advocacy Coalition Approach"; sino por las relaciones de poder, las prácticas y habitus de negociación de los diferentes actores, las cuales se traducen en estrategias.

Es por ello, que en un país con una débil construcción de ciudadanía, la teoría de "Advocacy Coalition Approach", no contribuye de manera suficiente a comprender la génesis de una ley. Puede corresponder a sociedades más pluralistas, pues su premisa principal es que la elaboración de políticas se produce en un subsistema en el que coexisten otras "coaliciones” que compiten entre sí a fin de influenciar leyes o políticas de acuerdo a sus propias creencias, lo que refuerza la cohesión de cada “coalición” (Sabatier, 1987). Aspecto este último no considerado en el caso de estudio, en donde los diversos actores fueron excluidos o no participaron en el proceso de problematización de la Ley (organizaciones sindicales, tecnócratas, expertos, académicos, organizaciones de la sociedad civil y medios de comunicación, entre otros, como actores que ejercen influencia en el subsistema político).

Cuarto, las prácticas y habitus de negociación de los diversos actores del campo político y de las relaciones laborales contribuyen a comprender las estrategias de los diversos actores en el proceso de génesis de una ley. Por ejemplo, habitus que llevan a las organizaciones sindicales a desinteresarse por la lucha en el campo 
jurídico; y explican la inercia institucional en términos de estrategias, lo cual lleva a desestimar este marco de oportunidad para intentar dar un giro diferente a la Ley.

Quinto, el proceso de conceptualización de una ley responde también a la reflexión realizada desde el campo académico, centrada -para el caso del mobbingen un problema interpersonal, desestimando el papel de las organizaciones como estructuras que lo favorecen o no. En este sentido, los procesos de aprendizaje adelantados en el campo científico y técnico cumplen un papel central en la formulación de la política y legislación pública, tal como lo señalan Paul A. Sabatier y Jenkins-Smith (1993).

Sexto, la débil fuerza jurídica de la Ley 1010 se sustenta, por un lado, en la conceptualización del acoso laboral el cual se aborda desde un enfoque interpersonal, desconociendo la responsabilidad de la empresa frente a este hecho; y el papel que ésta juega como institución que genera normas, habitus y prácticas que pueden favorecer el acoso laboral. Por otro lado, en la dificultad para adquirir la prueba, lo cual resta posibilidades de objetivar social y jurídicamente este tipo de violencia. Por último, los mecanismos de sanción y reparación del daño contemplados en la Ley son casi inexistentes. Aspectos todos ellos que restan capacidad coercitiva al instrumento legal.

Séptimo, la exclusión de los actores sociales directamente afectados en el proceso de génesis y problematización de la Ley, desencadena en un débil reconocimiento social. De ahí que el acoso laboral aún no se ha hecho visible, no se ha convertido de manera suficiente en un problema digno de ser atendido por el campo laboral, tanto por parte de empresarios como de los representantes de los trabajadores en Colombia. De ahí que muchos trabajadores y trabajadoras sigan vivenciando de manera silenciosa el desprestigio y el estigma social asociado a estos actos de violencia en el trabajo.

Octavo, al bajo reconocimiento social de la Ley se suma su limitada legitimidad por parte de los operadores judiciales, quienes ven la Ley como un instrumento que limita jurídicamente los procesos de sanción y reparación. Consecuencia de ello los hechos de acoso laboral acaban, con frecuencia, tipificados a través de normas diferentes de la Ley 1010.

Noveno, a pesar de las limitaciones jurídicas de la Ley 1010, ésta puso en escena en el país el mobbing como un problema social, el cual requería políticas de prevención, corrección y sanción. Sin duda este es uno de sus grandes aportes.

Cabe reflexionar también en torno al alcance de la reflexión realizada. Las dificultades halladas en la génesis de la Ley de Acoso Laboral en Colombia podrían tener dimensiones en común con las que se dan en otros problemas de derechos y normas laborales. Incluso con otras problemáticas en términos de derechos humanos que se han tratado de abordar desde la elaboración de instrumentos jurídicos (Ley de víctimas y restitución de tierras). Esto evidencia la distancia entre el campo jurídico y el social, en especial en países en donde la construcción de la ciudadanía es endeble. 
Los aspectos señalados plantean nuevas preguntas de investigación. La primera, tiene que ver con la manera de superar estas dificultades. Imaginando un escenario de aprobación de una nueva norma o reforma de la existente, ¿qué papel pueden tener los trabajadores, las fuerzas sindicales, las organizaciones empresariales, el gobierno, las víctimas o los operadores judiciales como actores en este nuevo proceso? ¿Cómo reconceptualizar el acoso laboral? ¿De qué manera podría impulsarse la sanción y la reparación del daño en ese nuevo instrumento legal?

De cara a responder las preguntas planteadas, puede ser recurrente la idea de realizar estudios que comparen las génesis y procesos de problematización dados en diferentes contextos nacionales. En relación con los resultados obtenidos en términos de prevención, reparación y judicialización de los hechos de acoso, así como de construcción como problema social en cada país.

\section{Anexo}

En la tabla $\mathrm{N}^{\mathrm{o}} 1$ se clasifican los representantes o senadores pertenecientes a la Coalición Uribista (CU) y a la Oposición (O).

Tabla Nº1 Tipo de Modificaciones Aprobadas al Proyecto de ley de Acoso laboral por agentes sociales

\begin{tabular}{|c|c|c|}
\hline $\begin{array}{c}\text { TIPO DE } \\
\text { MODIFICACIÓN }\end{array}$ & CONTENIDO & $\begin{array}{l}\text { AUTOR/ES DE } \\
\text { LA } \\
\text { PROPUESTA }\end{array}$ \\
\hline \multirow{4}{*}{ POSITIVAS } & $\begin{array}{l}\text { Definición de inequidad laboral y desprotec- } \\
\text { ción laboral como dos modalidades nuevas, } \\
\text { Artículo } 2^{\circ} \text {. }\end{array}$ & $\begin{array}{lr}\text { Repres. } & \text { C. } \\
\text { Augusto Celis } \\
\text { (Partido de la U) } \\
\text { (CU). }\end{array}$ \\
\hline & $\begin{array}{l}\text { Añadir el impacto a la salud física y psíquica } \\
\text { como agravante adicional a los presentados en } \\
\text { el Artículo } 4^{\circ} \text {. }\end{array}$ & $\begin{array}{l}\text { Senador B. A. } \\
\text { Guerra (Partido } \\
\text { Liberal) (O). }\end{array}$ \\
\hline & $\begin{array}{l}\text { Establecimiento de una suspensión provisional } \\
\text { del funcionario acosador cuando existen } \\
\text { indicios de actitudes retaliatorias (Parágrafo } 2 \\
\text { del Artículo } 10^{\circ} \text { ). }\end{array}$ & $\begin{array}{l}\text { Senador L. C. } \\
\text { Avellaneda } \\
\text { (Polo) (O). }\end{array}$ \\
\hline & $\begin{array}{l}\text { Suspensión de la evaluación por desempeño } \\
\text { para las víctimas (Artículo } 16^{\circ} \text { ). }\end{array}$ & $\begin{array}{l}\text { Senador } \text { B. } \\
\text { A.Guerra, } \\
\text { Partido Liberal } \\
\text { (O). }\end{array}$ \\
\hline \multirow{2}{*}{ NEGATIVAS } & $\begin{array}{l}\text { Aumento de la relación de atenuantes(Artículo } \\
3^{\circ} \text { ) }\end{array}$ & COLEGA \\
\hline & Añadido de un nuevo atenuante (Artículo 3º). & $\begin{array}{ll}\text { Senador L.C, } \\
\text { Avellaneda }\end{array}$ \\
\hline
\end{tabular}




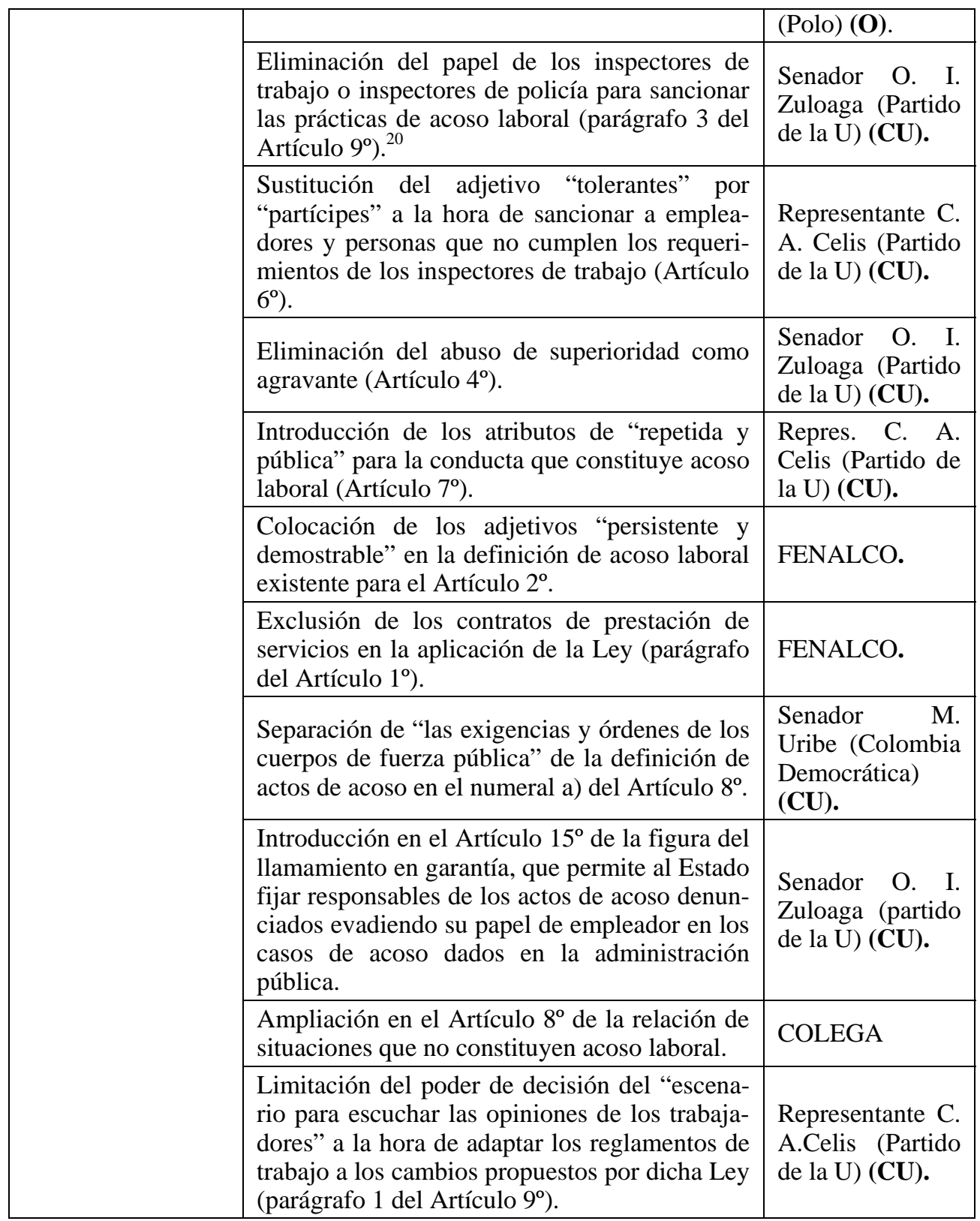

${ }^{20}$ Más que una modificación negativa, es una aclaración procedimental, pues el Ministerio no tiene la potestad de sancionar derechos que no son ciertos. 


\begin{tabular}{|c|c|c|}
\hline & $\begin{array}{l}\text { Colocación del atributo "serios" en el parágra- } \\
\text { fo } 2 \text { del Artículo } 10^{\circ} \text { respecto a los indicios } \\
\text { para la suspensión cautelar del funcionario } \\
\text { acosador }\end{array}$ & $\begin{array}{l}\text { Senador J. C. } \\
\text { Rodríguez } \\
\text { (Partido de la U) } \\
\text { (CU). }\end{array}$ \\
\hline & $\begin{array}{l}\text { Eliminación de la función de los inspectores } \\
\text { de trabajo para trasladar de lugar de trabajo a } \\
\text { los denunciantes (parágrafo } 3 \text { del Artículo } 9^{\circ} \text { ) }\end{array}$ & $\begin{array}{l}\text { Repres. C. A. } \\
\text { Celis (Partido de } \\
\text { la U) (CU). }\end{array}$ \\
\hline & $\begin{array}{l}\text { Impedir a terceros poner en conocimiento de } \\
\text { las autoridades los casos de acoso laboral } \\
\text { (numeral } 2 \text { del Artículo } 9^{\circ} \text { ). }\end{array}$ & FENALCO. \\
\hline
\end{tabular}

Fuente: elaboración propia. CU: Coalición Uribista. C: Oposición.

Tabla No 2 Modificaciones No Aprobadas al proyecto de ley de Acoso laboral por agentes sociales

\begin{tabular}{|c|c|}
\hline CONTENIDO DE LA MODIFICACIÓN & $\begin{array}{l}\text { AUTOR/ES DE LA } \\
\text { PROPUESTA }\end{array}$ \\
\hline $\begin{array}{l}\text { Especificar que puedan aceptarse medios de prueba en el } \\
\text { ámbito privado (Artículo } 6^{\circ} \text { ). }\end{array}$ & $\begin{array}{l}\text { Senador L. C. Avellaneda } \\
\text { (Polo) (O). }\end{array}$ \\
\hline $\begin{array}{l}\text { oso laboral las burlas en el ámbito } \\
\text { el Artículo } 7^{\circ} \text { ). }\end{array}$ & $\begin{array}{l}\text { Senador L. C. Avellaneda } \\
\text { (Polo) (O). }\end{array}$ \\
\hline $\begin{array}{l}\text { Eliminar los términos “en presencia de compañeros” para } \\
\text { la descalificación humillante (numeral f del mismo Artícu- } \\
\text { lo). }\end{array}$ & $\begin{array}{l}\text { Senador L. C. Avellaneda } \\
\text { (Polo) (O). }\end{array}$ \\
\hline $\begin{array}{l}\text { Suprimir el carácter } \\
\text { la definición del Art }\end{array}$ & $\begin{array}{l}\text { Senador L. C. Av } \\
\text { (Polo) (O). }\end{array}$ \\
\hline $\begin{array}{l}\text { Eliminar "la formulación de exigencias razonables de } \\
\text { fidelidad laboral o lealtad empresarial e institucional" } \\
\text { (numeral c del Artículo } 8^{\circ} \text { ) como una de las conductas que } \\
\text { no constituyen acoso laboral. }\end{array}$ & $\begin{array}{l}\text { Senador L. C. Avellaneda } \\
\text { (Polo) (O). }\end{array}$ \\
\hline $\begin{array}{l}\text { Se sugiere más precisión en la definición de acoso laboral } \\
\left(\text { Artículo } 2^{\circ} \text { ). }\right.\end{array}$ & $\begin{array}{l}\text { Presidente del Dpto. Admi- } \\
\text { nistrativo de la Función } \\
\text { Pública (DAFP) }\end{array}$ \\
\hline $\begin{array}{l}\text { Sustituir el verbo presumir del encabezamiento del Artículo } \\
7^{\circ} \text { (Conductas que constituyen acoso laboral: “se presumirá } \\
\text { que hay acoso laboral si se acredita la ocurrencia...”). }\end{array}$ & Presidente del DAFP. \\
\hline $\mathrm{Au}$ & $\begin{array}{l}\text { Senador J. C. Rodrígu } \\
\text { (Partido de la U). (CU). }\end{array}$ \\
\hline
\end{tabular}

Fuente: Elaboración propia. 
FENALCO: Federación Nacional de Comerciantes.

Partido de la U: en ese momento hacía parte de la coalición del gobierno del presidente Uribe.

Partido Colombia Democrática: hacía parte de la coalición que respalda el gobierno del presidente Uribe.

Partido Liberal: hacía parte de la oposición del gobierno.

Polo Democrático Alternativo (P.D.A): fuerza de izquierda opositora al gobierno del presidente Uribe.

\section{Bibliografía}

Abril, G. (1999). Análisis semiótico del discurso. En Delgado, J.M. y Gutiérrez, J. (coord.), Métodos y técnicas cualitativas de investigación socia (pp. 427-464). Madrid: Síntesis.

Alonso, L.E. (1995). Sujeto y Discurso: el lugar de la entrevista abierta en las prácticas de la sociología cualitativa. En Delgado, J.M. y Gutiérrez, J. (coord.) Métodos y Técnicas Cualitativas en Ciencias Sociales (pp. 225-240). Madrid: Síntesis.

Aramburu, L.; Higuera, Z. (2002). Respuesta al acoso laboral. Programas y estrategias. Cuadernos de Relaciones Laborales, Vol. 20 Núm. 2, 337-350

Bourdieu, P. (2000). Elementos para una sociología del campo jurídico. En Bourdieu, P. y Teubner, G. (coord.) La fuerza del derecho (pp. 153-220). Bogotá: Uniandes.

Bourdieu, P. (2001a). Las estructuras sociales de la economía (trad. Horacio Pons). Buenos Aires: Ediciones Manantial, tercera edición.

Bourdieu, P. (2001b). Poder, derecho y clases sociales, (trad. Andrés García Inda). Bilbao: Editorial Desclée de Brouwer.

Cámara de Representantes (2004a). Exposición de motivos del Proyecto 088 de 2004. Bogotá: inédito.

Cámara de Representantes (2004b). Ponencia para primer debate al Proyecto de ley 88 de 2004. Bogotá: inédito.

Cámara de Representantes (2004c). Informe de ponencia para segundo debate al Proyecto de ley 88 de 2004. Bogotá: inédito. 
Cámara de Representantes (2005). Acta de la Comisión 41 de la Cámara. Primer debate del Proyecto 088 de 2004. Bogotá: inédito.

Catani, M. (1990). Algunas precisiones sobre el enfoque biográfico oral. Revista Historia y Fuente Oral, 3(1), 51-164.

Colombia. Corte Constitucional (1997). Sentencia C-154 de 1.997.

Colombia (2006). Ley 1010 de 2006, de 23 de Enero, por medio de la cual se adoptan medidas para prevenir, corregir y sancionar el acoso laboral y otros hostigamientos en el marco de las relaciones de trabajo. Diario Oficial 46.160, Enero 23.

Colombia, Ministerio de la Proteccion Social (2008). Resolución 2646, por la cual se establecen disposiciones y se definen responsabilidades para la identificación, evaluación, prevención, intervención y monitoreo permanente de la exposición a factores de riesgo psicosocial en el trabajo y para la determinación del origen de las patologías causadas por el estrés ocupacional. Disponible en: http://www.alcaldiabogota.gov.co/sisjur/normas/Normal.jsp?i=31607>, acceso 17 de Julio de 2008.

Colombia. Ministerio del Trabajo (2012a): Resolución 652, por la cual se establece la conformación y funcionamiento del Comité de Convivencia Laboral en entidades públicas y empresas privadas y se dictan otras disposiciones. 30 de Abril de 2012 (en línea). http://www.usofrenteobrero.org/pdf/bfobarranca/ resolucion652de2012.pdf, acceso 6 de Junio de 2012.

Colombia. Ministerio del Trabajo (2012b). Resolución 1356, por la cual se modifica parcialmente la Resolución 652 de 2012 (en línea). http://www.cancilleria.gov.co/sites/default/files/Normograma/docs/resolucion_m tra_1356_2012.htm, acceso 5 de Agosto de 2012.

Colombia. Ministerio del Trabajo (2012c). Investigaciones administrativas laborales por acoso laboral por departamento y género: 2010 a marzo 2012. Bogotá: inédito.

Corporación Nuevo Arco Iris (2010). La relación entre el conflicto armado y la victimización de los trabajadores sindicalizados 1984 y 2009. Bogotá: PNUD. Disponible: http://pnud.org.co/2012/informes/CNAI/Informe\%20Final.pdf.

Cuyana, T. (2011). Críticas y perspectivas de la Ley 1010 de 2006: una aproximación desde la definición jurídica y psicológica del acoso laboral. Bogotá: Facultad de Jurisprudencia, Universidad del Rosario. 
De la Rota, M. E. et al. (2010). Evaluación de la judicialización de delitos contra trabajadores sindicalizados. Bogotá: Proyecto PNDU. Disponible en: <http://pnud.org.co/2012/informes/DEJUSTICIA/Informe\%20Final.pdf>

Dombois, R. ; Pries, L. (2000). Relaciones laborales entre mercado y Estado, sendas de transformación en América Latina. Caracas: Nueva Sociedad.

Dombois, R. (2012). Violencia contra sindicalistas. Observaciones sobre el proyecto del PNUD. Revista Controversia $N^{\circ} 198, .111-160$.

ENS (2010). Violencia antisindical e impunidad durante los 8 años del Gobierno Uribe. Disponible en:

$<$ http://www.uniglobalunion.org/Apps/UNINews.nsf/vwLkpById/8424D303724 6F0F8C1257786000EDD7B/\$FILE/Balance+Gobierno+Uribe.+Violencia+antis indical+e+impunidad.Textos+ENS.pdf $>$.

Foucault, M. (1999). Estética, Ética y Hermenéutica. Barcelona: Paidós.

Hirigoyen, M.F. (1999). El acoso moral, el maltrato psicológico en la vida cotidiana (trad. Enrique Folch González). Barcelona: Editorial Paidós Ibérica.

Ibáñez, T. (1996). Algunos comentarios en torno a Foucault. En Ibáñez, T. e Ibáñez Gracia, T. (coord.) Fluctuaciones conceptuales en torno a la postmodernidad y la psicología (pp. 43-60). Ciudad de México: Universidad Nacional Autónoma de México.

Lenoir, R. (1993). Objeto sociológico y problema social. En Lenoir, Remi, Merllié, Dominique y Pinto, Louis, Introducción a la práctica sociológico (pp. 57-101). México: Siglo XXI Editores.

Leymann, H. (1996). The content and development of mobbing at work University of Umeå, Sweden. European Journal of Work and Organizational Psychology, $5,165-184$.

Liefooghe, A.; Mackenzie, D. (2001). Accounts of workplace bullying: The role of the organization. European Journal of Work and Organizational psychology, 10 (4), 375- 392.

López, C.M.; Seco, E.; Ramírez, D. (2011). Prácticas de acoso laboral en empresas colombianas: una mirada estructural e inter-subjetiva. Revistas Cuadernos de Administración, 24(43), 307-328. 
López, C.M. (2002). Las relaciones laborales en Colombia: opciones estratégicas de los actores. Madrid: Universidad Complutense. Disponible en: < http://eprints.ucm.es/tesis/cps/ucm-t26088.pdf.>

Manguineau, D. (1999). Términos claves del análisis de discurso. En Abril, G. (ed.), Análisis semiótico del discurso (pp. 5 -15). Buenos Aires: Nueva Visión.

Martín, M.; Pérez, S. (2002). El acoso moral en el trabajo: la construcción social de un fenómeno. Cuadernos de Relaciones Laborales Vol. 20 Núm. 2, 271-302.

Motta, F. (2008). El acoso laboral en Colombia. Revista Via Iuris, Nº4, 92-105.

OIT (1981). Convenio 155 sobre seguridad y salud de los trabajadores. Disponible en: $<$ http://www.ilo.org/dyn/normlex/es/f?p=1000:12100:0::NO::P12100_INSTRU MENT_ID:312300, acceso 12 de Julio de 2012>.

OIT (1998). Declaración de la OIT relativa a los principios y derechos fundamentales en el trabajo. Disponible en: <http://www.ilo.org/public/spanish/standards/relm/ilc/ilc86/com-dtxt.htm> acceso 12 de Julio de 2012.

OIT (2012). Observaciones de la CEACYR sobre los Convenios Fundamentales 1990-2010. Disponible en:

$<$ http://white.oit.org.pe/spanish/260ameri/oitreg/activid/proyectos/actrav/proyect os/aplicum/reportes/reporte_12.php?language=ES\&idcountry=CO $>$, acceso 13 de Junio de 2012.

Palacios, M. (1995). Entre la legitimidad y la violencia 1875-199. Bogotá: Colección Vitral, Grupo Editorial Norma.

PNUD (2010). Construir el futuro, Informe sobre violencia contra sindicalistas y trabajadores sindicalizados 1984 - 2011. Bogotá: PNUD. Disponible en: < http://www.pnud.org.co/2012/informe_sindicalismo.pdf >

República de Colombia (2005a). Estudio de Antecedentes en el Senado del Proyecto de Ley 236 de 2005. Gaceta del Congreso: 1-68

República de Colombia (2005b). Acta Comisión Séptima del Senado ( ${ }^{\circ} 04$ de 2005). Primer debate Proyecto 235 de 2005”. Gaceta del Congreso, 61, 50-66.

República de Colombia (2006). Acta de la Plenaria del segundo debate al Proyecto de Ley 236 de 2005 en el Senado, Gaceta del Congreso, 29, 17-18. 
Sabatier, P. (1987). Knowledge, Policy-Oriented Learning and Policy Change. Knowledge 8, June, 649-692.

Sabatier, P.; Hank, C.; Jenkins, S. (1993). Policy change and learning: Anadvocacy coalition approach. Oxford: Westview Press.

Senado de la República (2005a). Ponencia para el primer debate del Proyecto de Ley 236 de 2005, Bogotá: inédito.

Senado de la República (2005b). Ponencia para el segundo debate del Proyecto de Ley 236 de 2005. Bogotá: inédito.

Zapf, D.; Gross, C. (2001). Conflict escalation and coping with workplace bullying: A replication and extension. European Journal of Work and Organizational Psychology, 10, 497-522. 